\title{
ARTICLE
}

Acute myeloid leukemia

\section{Integrated nuclear proteomics and transcriptomics identifies S100A4 as a therapeutic target in acute myeloid leukemia}

\author{
Bader Alanazi ${ }^{1} \cdot$ Chinmay R. Munje ${ }^{1,2} \cdot$ Namrata Rastogi $^{1} \cdot$ Andrew J. K. Williamson $^{3} \cdot$ Samuel Taylor $^{3} \cdot$ Paul S. Hole $^{1}$ • \\ Marie Hodges ${ }^{1,4}$. Michelle Doyle ${ }^{1,4} \cdot$ Sarah Baker ${ }^{1,4}$. Amanda F. Gilkes ${ }^{1,4} \cdot$ Steven Knapper ${ }^{1}$. Andrew Pierce ${ }^{3}$. \\ Anthony D. Whetton ${ }^{3} \cdot$ Richard L. Darley ${ }^{1} \cdot$ Alex Tonks (i) ${ }^{1}$
}

Received: 13 May 2019 / Revised: 18 September 2019 / Accepted: 30 September 2019 / Published online: 14 October 2019

(c) The Author(s) 2019. This article is published with open access

\begin{abstract}
Inappropriate localization of proteins can interfere with normal cellular function and drive tumor development. To understand how this contributes to the development of acute myeloid leukemia (AML), we compared the nuclear proteome and transcriptome of AML blasts with normal human $\mathrm{CD} 34^{+}$cells. Analysis of the proteome identified networks and processes that significantly affected transcription regulation including misexpression of 11 transcription factors with seven proteins not previously implicated in AML. Transcriptome analysis identified changes in 40 transcription factors but none of these were predictive of changes at the protein level. The highest differentially expressed protein in AML nuclei compared with normal $\mathrm{CD}_{3} 4^{+}$nuclei (not previously implicated in AML) was S100A4. In an extended cohort, we found that overexpression of nuclear S100A4 was highly prevalent in AML (83\%; 20/24 AML patients). Knock down of S100A4 in AML cell lines strongly impacted their survival whilst normal hemopoietic stem progenitor cells were unaffected. These data are the first analysis of the nuclear proteome in AML and have identified changes in transcription factor expression or regulation of transcription that would not have been seen at the mRNA level. These data also suggest that S100A4 is essential for AML survival and could be a therapeutic target in AML.
\end{abstract}

\section{Introduction}

Acute myeloid leukemia (AML) is a disorder arising from developmental arrest of cells of the myeloid lineage [1]. The realization that treatment with conventional cytotoxic agents

These authors contributed equally: Bader Alanazi, Chinmay R. Munje

Supplementary information The online version of this article (https:// doi.org/10.1038/s41375-019-0596-4) contains supplementary material, which is available to authorized users.

Alex Tonks

tonksa@cf.ac.uk

1 Department of Haematology, Division of Cancer \& Genetics, School of Medicine, Cardiff University, Cardiff CF14 4XN Wales, UK

2 Paul O'Gorman Leukaemia Research Centre, University of Glasgow, Glasgow G12 0ZD, UK

3 Stoller Biomarker Discovery Centre, The University of Manchester, Manchester M20 3LJ, UK

4 Cardiff Experimental and Cancer Medicine Centre (ECMC), School of Medicine, Cardiff University, Cardiff CF14 4XN Wales, UK has likely reached its limits in terms of delivering patient benefit, has fueled a drive towards understanding the complex and highly heterogeneous molecular mechanisms underlying AML with the aim of delivering more targeted therapeutic approaches. Whilst common mutations have been characterized in AML [2]; it is generally acknowledged that these are unable to fully account for the highly heterogeneous nature of this disease [3]. Messenger RNA abundance can be used as an alternative strategy for target identification but mRNA levels are not powerful predictors of protein expression [4]. Further, aberrant localization of proteins to the nucleus can alter their function to induce cancer development, block in hemopoietic development, or diminish tumor suppressor function [5]. Therefore, transcriptional profiling alone is an inefficient tool for target discovery and is often combined with alternative technologies [6]. Advances in mass-spectrometry (MS) based technologies have allowed researchers to characterize and identify proteins in complex biological samples providing direct data on relative protein abundance [7].

Given that inappropriate localization of cancer-related proteins, including oncoproteins and tumor suppressor proteins may interfere with normal cellular function, we 
hypothesized that the developmental arrest, sustained proliferation, and prosurvival characteristics of AML blasts may in part be mediated through misexpression or mislocalization of proteins to the nucleus. The aim of this study was to identify new therapeutic targets in AML through examination of the abundance of proteins in the nuclei of AML blasts using MS proteomics. We used isobaric tags for relative and absolute quantification (iTRAQ) together with liquid chromatography-tandem MS (LC-MS/MS) to analyze the nuclear proteome of the minimally differentiated AML blasts in comparison with developmentally-matched human CD $34^{+}$ hemopoietic stem/progenitor cells. A parallel transcriptome analysis was performed to correlate the protein data with transcriptional changes. Using this approach, we identified over 110 commonly misexpressed nuclear proteins including known abnormalities (such as WT1 and CEBPA) and novel abnormalities such as NFIC, hnHRPs. The most strongly over-expressed (novel) protein in the nucleus of AML patients was S100A4 (aka metastasin, MTS-1).

S100A4 is a $\sim 11 \mathrm{kDa}$ protein which belongs to the $S 100$ multigene family of calcium-binding proteins of the EFhand type (reviewed in [8]). They have diverse roles in a variety of cellular processes including regulation of proliferation, cell cycle progression, apoptosis, differentiation, $\mathrm{Ca}^{2+}$ homeostasis, migration, adhesion, and transcription but little is known of its role or subcellular expression in hemopoiesis $[9,10]$. S100A4 has been previously associated with poor prognosis in several solid tumors [11-14] and in leukemia $[15,16]$. The functional implication of altered S100A4 expression, subcellular localization, and mechanisms of action in cancers (especially leukemia) remain unidentified. Here we identified a potential role for S100A4 and provide evidence supporting its clinical significance in AML.

\section{Materials and methods}

\section{Primary cell material and cell culture}

Diagnostic bone marrow or peripheral blood from AML patients and cord blood were collected with informed consent; patient clinical characteristics were outlined in Supplementary Methods. Normal human $\mathrm{CD} 4^{+}$cells were isolated as previously described [17].

Cell lines were obtained from ECACC ${ }^{\mathrm{TM}}$ (Salisbury, UK) or ATCC (Middlesex, UK) and cultured under recommended conditions. The genetic identity of the cell lines was confirmed by short tandem repeat (STR). Cells at passages greater than twenty were not used in the experiments performed in this study. Monitoring for Mycoplasma contamination was performed using the MycoAlert Detection
Kit (Sigma). S100A4 harboring a nuclear localization sequence (NLS) was expressed utilizing retroviral and lentiviral vectors co-expressing GFP as a selectable marker (Supplementary Methods). For knock down studies, Mission $^{\circledR}$ shRNA vectors based on TRC(1)2-pLKO.5-puro (S100A4 shRNA and nonmammalian shRNA control) were purchased from Sigma-Aldrich, Dorset, U.K. CD34 ${ }^{+}$cells and cell lines were transduced and cultured as previously described [17, 18].

\section{Protein extraction, western blotting, and mass spectrometry}

Nuclear and cytoplasmic proteins were isolated from $>5 \times$ $10^{6}$ fresh/frozen $\mathrm{CD} 34^{+}$cells and AML blasts using the Nuclear/Cytosol Fractionation Kit (Cambridge Bioscience, U.K.) following manufacturer's instructions. A fraction of AML cells were also lysed in Trizol $^{\circledast}$ for comparative mRNA analysis (Supplementary Methods) [18].

Western blotting was carried out as previously described [19] with the following antibodies: anti-S100A4 (clone D9F9D, Cell Signaling Technologies (CST), Netherlands), Histone H1 (clone AE-4, AbD Serotec, U.K.), H3 (CST), and glyceraldehyde-3-phosphate dehydrogenase (GAPDH) (6C5, Santa Cruz Biotechnology, Heidelberg, Germany).

Detailed MS proteomic methods and data analysis are shown in Supplementary Methods. The MS proteomics data have been deposited to the ProteomeXchange Consortium (http://proteomecentral.proteomexchange.org) via the PRIDE partner repository with the data set identifier PXD002799.

\section{GeneChip $^{\circledR}$ expression profiling (GEP)}

RNA isolation and GEP using Affymetrix Human Transcriptome Array 2.0 GeneChips $^{\circledR}$ was performed as detailed in Supplementary Methods. All data were analyzed using Partek Genomics Suite Software using Gene Expression workflow (v6.6; Partek Inc., MO, USA). Significant differences were determined by ANOVA and a $> \pm 1.5$ fold changes in AML vs. CD34 $4^{+}$. Data is available as supplementary material at https://www.ebi.ac.uk/arrayexpress/ under the following Accession Number: E-MTAB-3873.

\section{Cell proliferation and viability assays}

Cells were seeded in triplicate in a 96-well flat-bottom tissue-culture plate in serum-replete growth media at $1.6-2 \times 10^{5}$ cells $/ \mathrm{mL}$ and incubated for up to $48 \mathrm{~h}$ post infection. Cultures were harvested and viable (propidium iodide (PI)-negative) cells were counted by flow cytometry. For apoptosis assays, Annexin V-APC in combination with PI staining was performed. 


\section{Flow cytometry}

Flow cytometric data were acquired using an Accuri $^{\mathrm{TM}}$ C6 cytometer (B.D. UK). Data was analyzed using FCS Express ${ }^{\circledR}$ v6 (De Novo Software, CA). The threshold for GFP positivity was determined from the autofluorescence of GFP negative or mock transduced cells. Supplier and isotype matched control stained cells were used to determine background of labeled cells. Debris and ejected nuclei were excluded from the analysis of $>10,000$ events.

\section{Statistical analysis}

Statistical significance of nonparametric data was analyzed by Mann-Whitney $U$-Test. Data represent mean $\pm 1 \mathrm{SD}$. Calculations were performed using Minitab ${ }^{\circledR}$ v16 (Minitab
Inc. USA). Network and Pathway data analysis was performed using Key Pathway Advisor and Metacore ${ }^{\mathrm{TM}}$ (Clarivate Analytics, UK).

\section{Results}

\section{Nuclear proteomics reveals novel proteins mis- expressed in AML}

We randomly selected 15 AML diagnostic samples from minimally differentiated leukemia patients (FAB type M1), to minimize variability arising from developmental differences. AML blasts were $>80 \%$ viable and did not express CD14 and CD15 (Fig. 1a) (as previously described [20]). For controls we used normal human CD34 ${ }^{+}$ cells; immunophenotypic analysis of these cells
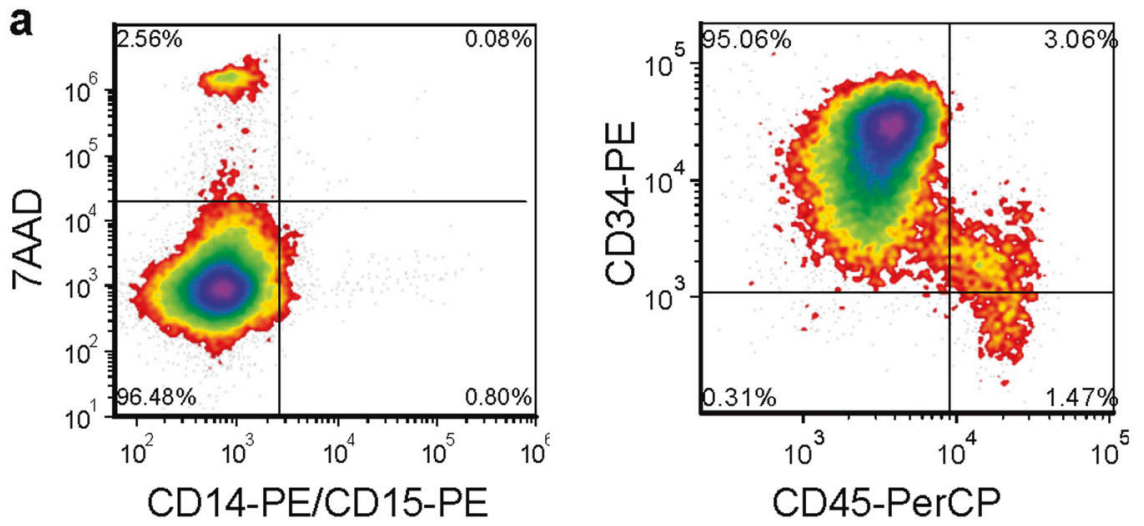

b

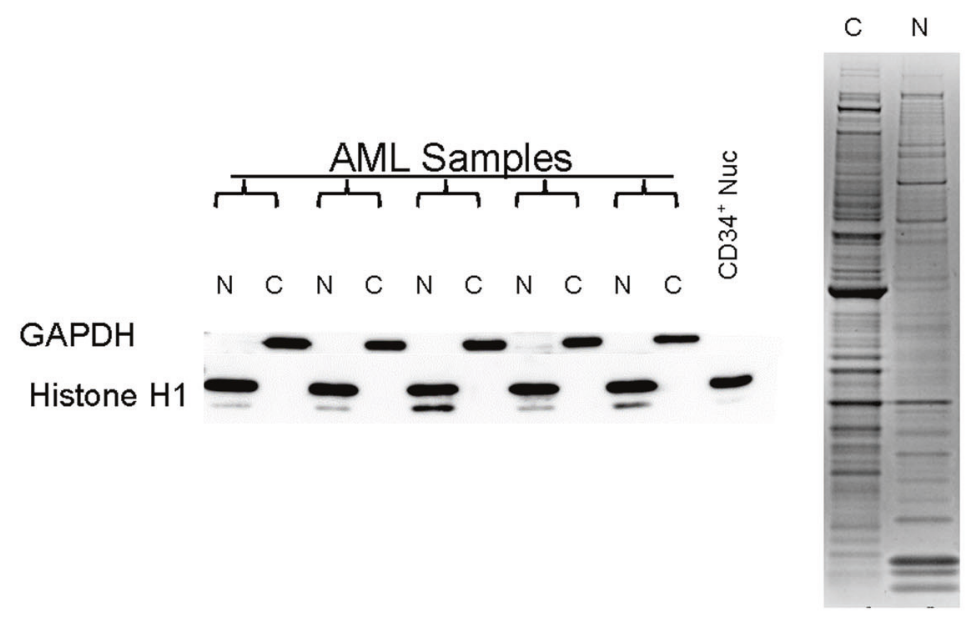

Fig. 1 Characterization and quality control of human $\mathrm{CD}^{+} 4^{+}$cells and patient AML blast samples. a Example bivariate flow cytometric plot showing viability and immunophenotype of AML blasts used in the study (left). FAB subtype (established by morphology) was confirmed by absence of CD14/CD15 expression [20]. Data exemplifying the purity of $\mathrm{CD} 34^{+}$cells is shown in the right panel. Quadrants delimit background isotype staining. b Example chromatograms of microcapillary electrophoresis using Agilent 2100 Bioanalyzer from representative RNA samples of AML patients. c Examples of fractionated protein purity and quality. Left panel shows nitrocellulose immunoblots of samples fractioned for nuclear $(\mathrm{N})$, or cytoplasmic $(\mathrm{C})$ proteins. Purity of the fractioned samples was assessed by immunoblotting for GAPDH and histone protein expression. Right panel shows overall protein profile and integrity quality determined through Coomassie Brilliant Blue $\mathrm{G}$ staining of polyacrylamide gels 
established all samples were $>95 \%$ viable and $95 \%$ $\mathrm{CD}^{+} 4^{+}$(Fig. 1a). For transcriptome analysis, defined high quality RNA was isolated from all samples (Fig. S1b). Isolation of nuclear proteins was carried out in parallel and extract purity confirmed using western blotting of cytoplasmic and nuclear protein markers (GAPDH and histone respectively). This analysis showed little or no apparent cytoplasmic contamination in the nuclear fraction (Fig. 1b). The quality of protein extracts was confirmed by polyacrylamide gel electrophoresis which showed the absence of detectable degradation (exemplified in Fig. 1b).

To identify differentially expressed proteins, eightchannel isobaric tagging coupled with LC-MS/MS was employed to simultaneously compare nuclear proteins from AML blast cells vs. normal CD $34^{+}$controls (Fig. S1a for workflow). Three separate iTRAQ datasets were acquired to analyze 15 AML samples and five controls. Protein Pilot was used to normalize each ion/peptide detected within the AML sample to the control(s) within each run to provide a ratio of $\mathrm{AML} / \mathrm{CD} 34^{+}$control. As expected, distributions of detectable peptide ratios from AML blasts vs. CD34 ${ }^{+}$(Fig. S1c) were similar, suggesting overall similarity within the proteome. A total of 4666 quantifiable proteins were identified from the nuclear samples (Table S1). Using peptides from $\mathrm{CD}^{+} 4^{+}$as internal controls we calculated the intra-experiment $90 \%$ confidence limits allowing us to determine if the protein(s) was significantly altered in AML blasts. We then identified frequently dysregulated proteins that changed in at least five AML patients ( $\pm>2$ fold) from at least two independent MS runs. Where an AML patient sample was compared with two $\mathrm{CD} 34^{+}$controls we accepted a protein as 'changed in AML' if changes against both controls were coincident. This yielded 113 proteins of which 84 (75\%) were designated nuclear proteins (Table S2).

Functional enrichment analysis of these 113 proteins showed that the most significant Gene Ontology 'Processes' and 'Networks' changed in AML patient blasts were related to Transcription, mRNA processing, and stabilization (Fig. 2a and Table S3). We observed changes in 13 heterogeneous nuclear ribonucleoproteins (hnRNP) affecting mRNA processing including: $\mathrm{A} 0, \mathrm{~A} 1, \mathrm{~A} 2 \mathrm{~B} 1, \mathrm{~A} 3, \mathrm{AB}, \mathrm{C}, \mathrm{D}$, DL, F, H1, M, R, and UL2. Enrichment by protein function showed that $\mathrm{TF}$ were the class of proteins most significantly enriched in our data set (Fig. 2a). We further analyzed the interactions of these 113 proteins with each other using MetaCore $^{\mathrm{TM}}$ analysis tool and the Direct Interaction algorithm and found a network of 40 protein interactions (Fig. 2b).

We identified three upregulated TF in leukemic cells compared with normal CD34 ${ }^{+}$cells (Table 1); of these, two had been previously associated with AML: CEBPA [21, 22] and WT1 [23, 24]. The third, Nuclear Factor IC (NFIC), has not been previously reported to be upregulated in AML. NFIC belongs to the NFI family which is composed of four members which differ in their ability to either activate or repress transcription (reviewed in [25]). We also identified eight down-regulated $\mathrm{TF}$, of which two have been previously associated with AML: HMGA2 [26] and BCL11A [27]. The remaining six downregulated proteins are novel abnormalities in AML: DAZAP1, ILF2, ILF3, hnRPDL, MYEF2, and TARDBP (Table 1).

To establish whether the protein expression changes identified above (Table S2) were transcriptionally driven, relative mRNA transcript abundance of AML blasts vs. $\mathrm{CD} 34^{+}$was analyzed. It has been previously established that mRNA expression is only predictive of protein expression in as little as $40 \%$ of genes [4]. Our data were in accord with this, with $60 \%$ agreement overall and 55\% concordance in our differentially expressed TFs with a protein/mRNA fold change $\geq \pm 1.3$ (Table 1 and Fig. 3a). This was not only a characteristic of TFs since $\sim 60 \%$ of the significantly expressed proteins identified from our dataset of 113 proteins did not correlate with changes in mRNA expression (Fig. 3b). While transcription can provide at least a partial explanation for changes in protein expression, these data suggest that posttranscriptional events are of equivalent importance in regulating protein abundance in AML.

\section{Identification of aberrantly expressed proteins driving transcriptional change in AML}

In order to functionally validate changes identified in Table 1, we carried out an unsupervised analysis of AML specific changes in the transcriptome using ANOVA and threshold analysis and coupled this with Metacore's ${ }^{\text {TM }}$ network building algorithm on TF. This analysis identifies over-connected networks of known interacting proteins within the significantly changing mRNA dataset. This approach revealed 311 TF (Table S4) and of those TF, 40 were found to be significantly changed in AML. Only the changes in CEBPA and WT1 expression functionally validated the change observed at the protein level. This suggests that the abundance of these two TF proteins correlates with changes in expression of known CEBPA and WT1 target genes. This analysis is however dependent on the level of annotation in the Clarivate knowledgebase and will be subject to bias towards frequently studied proteins [28]. In light of this we tried an alternative approach to identify aberrant driver TF activity by using a causal reasoning algorithm (Key Pathway Advisor) to identify upstream regulators that are responsible for influencing the changes in nuclear protein expression observed in AML (Table S5); however, these key hubs (the most significant of which was 


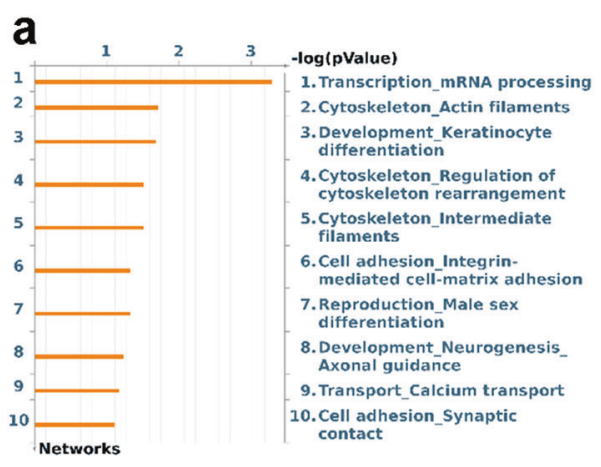

\begin{tabular}{|l|r|c|r|}
\hline \multicolumn{1}{|c|}{ Protein class } & \multicolumn{1}{|c|}{ Actual } & p-value & z-score \\
\hline Transcription factors & 11 & $7.886 \mathrm{E}-04$ & 4.077 \\
\hline Ligands & 4 & $6.844 \mathrm{E}-02$ & 2.007 \\
\hline Proteases & 4 & $9.841 \mathrm{E}-02$ & 1.721 \\
\hline Enzymes & 12 & $1.099 \mathrm{E}-01$ & 1.43 \\
\hline Receptors & 2 & $1.341 \mathrm{E}-01$ & -1.316 \\
\hline Other & 80 & $8.942 \mathrm{E}-03$ & -2.585 \\
\hline
\end{tabular}

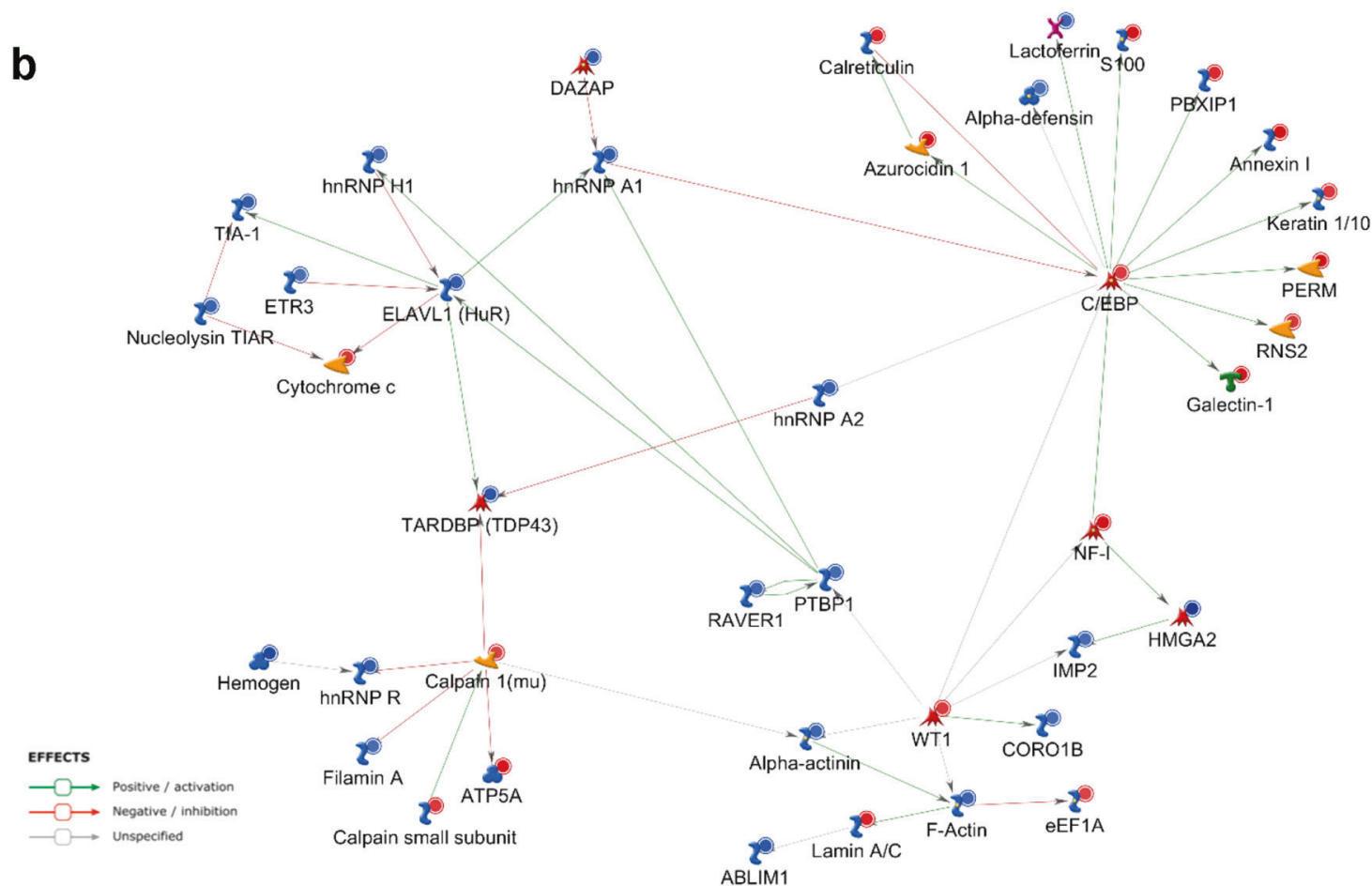

Fig. 2 Functional enrichment analysis of protein changes observed in AML vs. normal hemopoietic $\mathrm{CD}_{3}{ }^{+}$cells using Metacore $^{\mathrm{TM}}$. a Enrichment analyses using Process Networks (left panel) and enrichment by protein function (right panel) shows that 'Transcription' is the most significant Network. The Network establishes relationships between the genes from the dataset but does not cluster them according to a specific pathway. A false discovery rate (FDR) of 0.05 was applied. b Protein networks associated with the proteins up- or downregulated in the nuclei of AML patient blasts. The network was generated using direct interaction algorithm of MetaCore ${ }^{\mathrm{TM}}$ (Clarivate

RNF4; Fig. S2) were also not predictive of the observed protein changes.

In summary, nuclear proteomics identified transcription as being the most dysregulated process in AML with both known and novel TF being implicated (see "Discussion"). Whilst we validated the role of the former (WT1, CEBPA) by analysis of the corresponding transcriptome, we were unable to achieve this with novel TF abnormalities (probably due to relatively poor database annotation for these proteins).

Analytics). Nodes represent proteins with lines between nodes indicating protein interactions. Only connected nodes are shown. Arrow heads indicate the direction of the interaction. Node shapes represent the functional class of the proteins as shown in the graphic key (Supplementary Fig. S2b). Red and blue circles indicate up and down regulation respectively when compared with $\mathrm{CD} 34^{+}$nuclei. Interactome analysis using "Transcription Factor" algorithm identified CEBPA $(p=5.285 \mathrm{e}-08)$ and WT1 $(p=0.002825)$ as the most significant connected transcription factors in our protein dataset

\section{S100A4 is over-expressed in the nucleus of AML blasts}

Having analyzed our data with respect to the most dysregulated process, we next investigated the most strongly changed proteins in AML compared with $\mathrm{CD} 34^{+}$cells (Table 2). Amongst the Top 10 changing proteins, we identified several proteins that have previously been implicated as an abnormality in AML (Supplementary Table S6). Among the previously non-implicated proteins, 
Table 1 Transcription factors frequently changed in the nucleus of patients with AML FAB M1

\begin{tabular}{|c|c|c|c|c|}
\hline Gene symbol & Gene name & Frequency & $\begin{array}{l}\text { Protein fold change } \\
\left(\mathrm{AML} \text { vs. CD } 34^{+}\right)^{\mathrm{a}}\end{array}$ & $\begin{array}{l}\text { Normalized gene expression } \\
\text { (fold change AML vs. CD } 34^{+} \text {) }\end{array}$ \\
\hline NFIC & Nuclear Factor I C & 6 & 5.5 & $1.5^{\mathrm{b}}$ \\
\hline WT1 & Wilms Tumor 1 & 8 & 2.9 & $5.6^{\mathrm{b}}$ \\
\hline CEBPA & $\begin{array}{l}\text { CCAAT/enhancer binding protein } \\
(\mathrm{C} / \mathrm{EBP}) \text {, alpha }\end{array}$ & 7 & 2.9 & $1.7^{\mathrm{b}}$ \\
\hline ILF3 & $\begin{array}{l}\text { Interleukin enhancer binding factor } \\
3,90 \mathrm{kDa}\end{array}$ & 8 & -2.4 & -1.2 \\
\hline ILF2 & Interleukin enhancer binding factor 2 & 7 & -2.7 & -1.2 \\
\hline hnRNPDL & $\begin{array}{l}\text { Heterogeneous nuclear ribonucleoprotein } \\
\text { D-like }\end{array}$ & 11 & -3.3 & -1.0 \\
\hline BCL11A & $\begin{array}{l}\text { B-cell CLL/lymphoma 11A (zinc finger } \\
\text { protein) }\end{array}$ & 8 & -3.3 & $-1.4^{\mathrm{b}}$ \\
\hline DAZAP1 & TAR DNA-binding protein 43 & 10 & -3.4 & -1.2 \\
\hline TARDBP & DAZ associated protein 1 & 9 & -3.8 & $1.3^{\mathrm{b}}$ \\
\hline MYEF2 & Myelin expression factor 2 & 10 & -5.4 & $-3.7^{\mathrm{b}}$ \\
\hline HMGA2 & High mobility group AT-hook 2 & 14 & -5.9 & $-3.0^{\mathrm{b}}$ \\
\hline
\end{tabular}

Proteins were selected based on those that significantly changed co-directionally $\pm>2$ fold between normal CD $34^{+}$control and AML in at least 5 of the 15 patients (frequency)

${ }^{a}$ Calculation based solely on patients where a significant change was observed to derive the average fold change of AML vs. CD34 ${ }^{+}$normal control. Also shown are the fold changes of normalized gene expression data of corresponding mRNA. Positive values are upregulated in AML vs. control. Negative values downregulated in AML vs. control

${ }^{\mathrm{b}}$ Genes considered to have a change in mRNA transcript abundance when analyzed by ANOVA $(P<0.05)$ and $\geq \pm 1.3$ fold compared with control

the highest differential expression was seen in S100A4 (Fig. 3c). S100A4 [29] was significantly upregulated in the nuclei of 11/15 AML patients with an average fold increase of 5.5 when compared with controls. We validated the expression of S100A4 in cytosolic and nuclear protein fractions using western blot from the same samples used for MS. As shown in Fig. 4a (and Fig. S3), S100A4 protein expression was observed in the nucleus of AML blasts (86\%; 13/15) supporting our MS data. In contrast, nuclear expression of S100A4 was undetectable in $\mathrm{CD} 34^{+}$controls. Interestingly, S100A4 expression was also increased in the cytoplasm of AML blasts versus normal controls. We confirmed this data in a second cohort of patient AML blasts which also showed nuclear overexpression in seven of seven patients; and in the cytosol of nine of nine patients (Fig. S3). To establish whether S100A4 was overexpressed in a broader cohort of AML patients with blast differentiation, we immunoblotted for S100A4 in FAB-M4 subtypes (Fig. S4). Again, we found this protein to be overexpressed in the nuclei of AML blasts (4/6 patients when compared with normal human differentiated monocytes (which had undetectable levels of nuclear S100A4 expression). We also observed S100A4 expression in all leukemia cell lines analyzed with six of the ten lines having prominent nuclear expression of the protein (Fig. $4 \mathrm{~b}, \mathrm{c}$ ).

Upregulation of S100A4 expression in patients is also supported by our transcriptome analysis of these samples (Fig. 5) indicating that overexpression arises at least partly at a transcriptional level. Analysis of several independent datasets supports the overexpression of S100A4 mRNA in AML (Figs. 5b(i) and S5). Further, data derived from (TCGA) [30, 31] suggests that overexpression may confer a poor prognosis $(P=0.0118$; Fig. $5 b)$.

In summary, nuclear overexpression of S100A4 is a very common abnormality in AML patients and AML cell lines.

\section{S100A4 expression is required for the growth and survival of AML cells but not for normal myeloid survival development}

The above data shows S100A4 is over-expressed in the nucleus in AML. To determine whether ectopic expression of nuclear S100A4 can affect the growth and survival of $\mathrm{CD} 34^{+}$cells, we attempted to overexpress nuclear-targeted S100A4 in normal human hemopoietic cells (Fig. S6a). Whilst, these vectors were able to express S100A4 in HEK293T (Fig. S6b); overexpression of S100A4 could not be demonstrated in transduced $\mathrm{CD}_{4}{ }^{+}$cells despite expressing GFP (Fig. S6c), probably due to rapid degradation of S100A4 protein in these cells.

Data from our previous microarray analysis [18] suggest differential expression of S100A4 mRNA in normal hemopoietic cell lineages (Fig. S7). Analysis at the protein level confirmed cytosolic expression in monocytic, erythroid and (weakly) in granulocyte progenitors as well as in normal bone marrow. Nuclear S100A4 was absent in all samples 


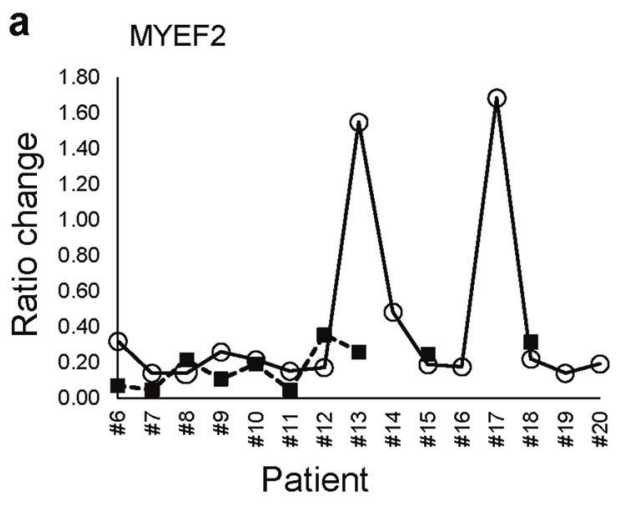

$-1-$ Protein

b

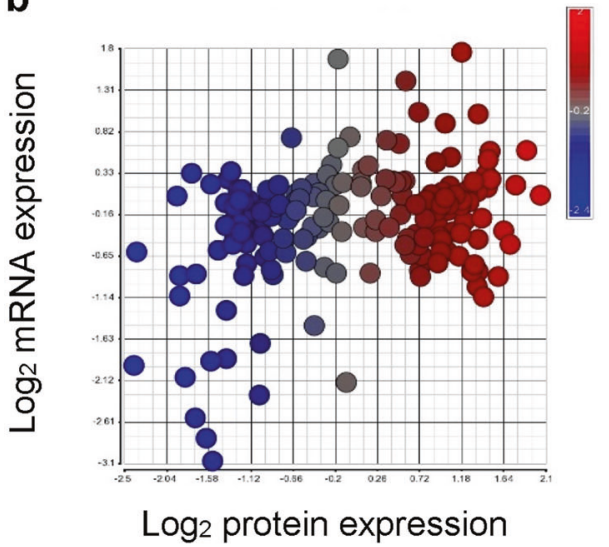

Fig. 3 Correlation of protein and mRNA transcript expression of nuclear proteins changed in AML. a Protein and mRNA expression changes in two transcription factors identified to be differentially expressed between AML blasts and normal human $\mathrm{CD} 34^{+}$cells using LC/LC-MS/MS. Values below one are repressed in AML blasts. Some patients do not have a significant detection of protein when analyzed by LC/LC-MS/MS. b Correlation of nuclear protein expression with mRNA expression in nuclear proteins identified to be significantly

(Fig. S7) suggesting that the nuclear localization of this protein in AML is aberrant. To address whether S100A4 protein was required for normal hemopoietic cell development, we knocked-down S100A4 expression in CD34 ${ }^{+}$ cells (Fig. S8). Whilst these cells grew slightly slower (but statistically not significant), we observed no significant effect on lineage development of these cells (Fig. S8) suggesting S100A4 is not required for normal hemopoiesis. Indeed, S100A4 knock out mice do not show any obvious phenotype at birth and develop normally [32].

We next examined the consequences of knocking down S100A4 expression in leukemia cell lines (Fig. 6a). In all lines, S100A4 knockdown significantly impaired the growth of these cells (Figs. 6b and S8). Further, KD of S100A4 in AML cells (KG1) with little S100A4 expression, showed no effect on proliferation. Using flow cytometric analysis of annexin $\mathrm{V}$ and PI staining, the percentage of cells in early or late apoptosis was determined (Fig. 6c). In

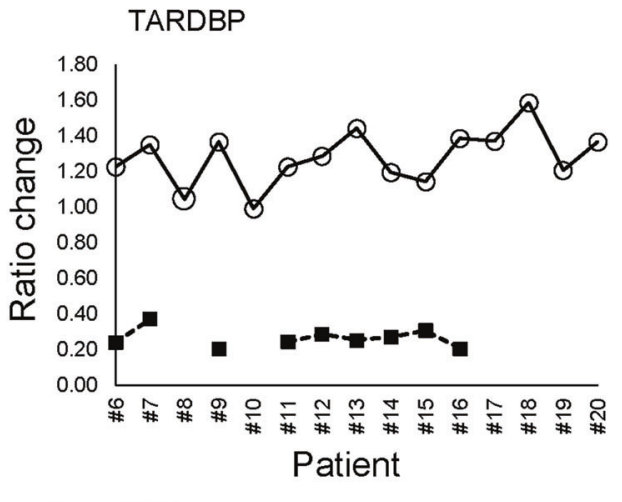

$\multimap$ mRNA

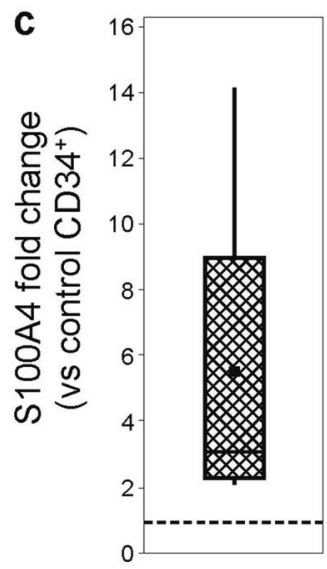

changed between AML and $\mathrm{CD} 34^{+}$cells. Legend depicts level of change in protein expression in AML vs. normal $\mathrm{CD}_{3} 4^{+}$cells. Negative values depict lower levels of expression in AML vs. CD34 ${ }^{+}$ cells. c Box and whisker plot show relative MS quantitation of S100A4 protein in expression in nuclear AML blasts vs. normal controls $(n=11)$. The dashed line represents no change to control $\left(\mathrm{CD} 34^{+}\right)$. Solid line indicates median and filled square indicates mean

all cell lines tested, loss of S100A4 expression induced annexin $\mathrm{V}$ positivity (Fig. 6d) suggesting that the lack of cell growth observed above was a result of programmed cell death. Taken together these data infer that S100A4 is required for AML cell survival but not for normal cells suggesting that targeting S100A4 would be an effective strategy in this disease.

\section{Discussion}

Given that developmental arrest is common to all AML and is mediated through misregulation of the differentiation program a number of groups have used transcriptome analyses such as oligonucleotide array or RNAseq for determining the genome wide gene expression [33-35]. However, it is becoming increasingly clear that analysis of mRNA alone is insufficient to predict biological function 
Table 2 Significantly changing nuclear proteins in AML patient blasts

\begin{tabular}{|c|c|c|c|c|c|}
\hline Gene symbol & Gene name & Frequency & $\begin{array}{l}\text { Fold change } \\
\left(\mathrm{AML} \text { vs. } \mathrm{CD} 34^{+}\right)^{\mathrm{a}}\end{array}$ & $\begin{array}{l}\text { Frequency } \times \text { fold } \\
\text { change }^{\neq}\end{array}$ & $\begin{array}{l}\text { Abnormally expressed } \\
\text { in } \mathrm{AML}^{\mathrm{b}}\end{array}$ \\
\hline HMGA2 & High mobility group protein HMGI & 14 & -6.0 & 84.7 & Yes \\
\hline ANXA1 & Annexin A1 & 11 & 6.3 & 69.6 & Yes \\
\hline PTRF & $\begin{array}{l}\text { Polymerase } \mathrm{I} \text { and transcript } \\
\text { release factor }\end{array}$ & 11 & -5.7 & 63.4 & Yes \\
\hline S100A4 & Protein S100-A4 & 11 & 5.5 & 60.5 & Not reported \\
\hline LSP1 & Lymphocyte-specific protein 1 & 13 & -4.2 & 54.8 & Yes \\
\hline MYEF2 & Myelin expression factor 2 & 10 & -5.4 & 54.1 & Yes \\
\hline MPO & Myeloperoxidase & 9 & 5.3 & 48.4 & Yes \\
\hline ANXA4 & Annexin A4 & 11 & 4.20 & 46.2 & Yes \\
\hline S100A6 & Protein S100-A6 & 11 & 3.89 & 42.8 & Not reported \\
\hline FLNB & Filamin B & 13 & -3.3 & 42.7 & Yes \\
\hline
\end{tabular}

The top 10 most significant protein changes are shown based on the ${ }^{\neq}$product of frequency of observation and magnitude of change (independent of direction of change). At a minimum, proteins must have significantly changed $\pm>2$ fold between normal CD34 $4^{+}$control and AML in at least 5 of the 15 patients (Frequency) derived from Supplementary Table S2

${ }^{a}$ Calculation based solely on patients where a significant change was observed to derive the average fold change of $\mathrm{AML}$ vs. CD34 ${ }^{+}$normal control. Positive fold change values are upregulated in AML vs. control. Negative values downregulated in AML vs. control

${ }^{\mathrm{b}}$ Literature references for proteins reported as an abnormality in AML are provided in Supplementary Table S6

given that mRNA expression does not always equate to protein expression and does not identify altered subcellular localization of proteins. In this study we have therefore, carried out proteomic analysis in tandem with transcriptomics and have focused on protein changes within the nuclear compartment which are otherwise underrepresented in whole cell proteomics.

Although model systems strongly implicate TF dysregulation in this disease, in patient material only a few common transcription factor abnormalities are known (e.g., PMLRARA, RUNX1-ETO, Inv16, CEPBA) and these are mainly associated with particular cytogenetic subsets of AML [36]. Therefore, large scale proteomic technologies are mainly used to quantify changes in protein abundance in in vivo or ES differentiation model systems [37-39]. However, the actual transcriptional environment in primary AML patient material characterized by the relative abundance of TF protein expression compared with normal blasts has not yet been described. However, the expression of some TF in AML and in normal $\mathrm{CD} 34^{+}$cells was recently described using reverse phase protein arrays using 228 validated antibodies [40]. Given that protein expression profiling patterns in AML correlate with morphologic features [41], we restricted our analysis to undifferentiated AML compared with normal human undifferentiated $\mathrm{CD} 34^{+}$cells to minimize changes as a result of differentiation. Using this approach, we identified significant differences in protein expression in GO processes involving mRNA stabilization. Further, we identified Networks enriched for transcription and observed significant differences in TF protein abundance in AML blasts including
CEBPA and WT1. Importantly, several new and novel TF which have not been previously reported as an abnormality in AML were identified, among these were ILF2, ILF3, TARDBP, hnRPDL, DAZAP1, MYEF2, and NFIC. Interleukin enhancer binding factor (ILF) 2 encodes a $45 \mathrm{kDa}$ protein and forms a complex with the $90 \mathrm{kDa}$ interleukin enhancer-binding factor 3 (ILF3). This has been shown to affect the redistribution of nuclear mRNA to the cytoplasm and to negatively regulate the microRNA processing pathway [42]. TAR DNA binding protein (TARDBP) is a RNAbinding protein that has multiple functions including transcription. Little is known about TARDP but strong expression of this protein has previously been shown in the nucleolus of AML cell lines [43]. hnRNPs comprise a family of RNAbinding proteins, which are involved in processing heterogeneous nuclear RNAs into mature mRNAs and act as transfactors in regulating gene expression. Within the nucleus these proteins are involved in RNA splicing, $3^{\prime}$-end processing, transcriptional regulation, and immunoglobulin gene recombination [44]. Recently, Gallardo et al. showed that AML patients harboring $9 \mathrm{q}$ deletions have decreased $H N R N P K$ expression implicating the role of this protein in the development of AML [45]. NFIC belongs to NFI family of transcription factors with associated members being NFIA, NFIB, and NFIX. Regulation of cellular differentiation is reported to be the fundamental function of these members [46]. NFIC has been shown to be upregulated in several solid tumors including gastric cancer, lung squamous cell carcinoma, and colorectal cancer and is correlated with increased expression of oncogenes [47, 48]. 
a

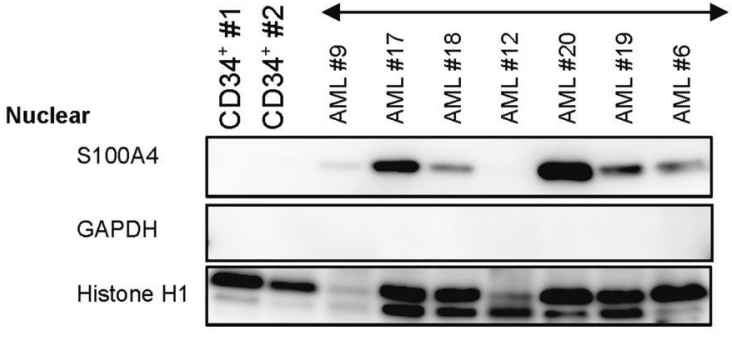

Cytoplasm

S100A4

GAPDH

Histone $\mathrm{H} 1$

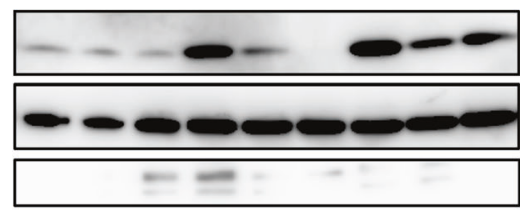

b

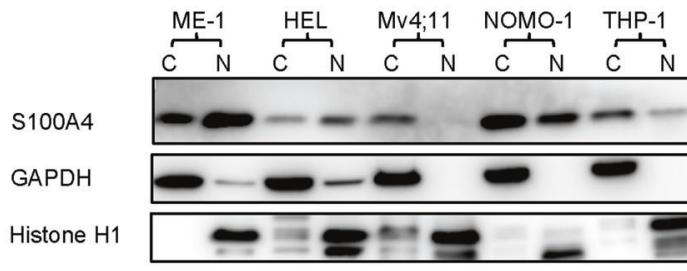

C

DAPI Tubulin
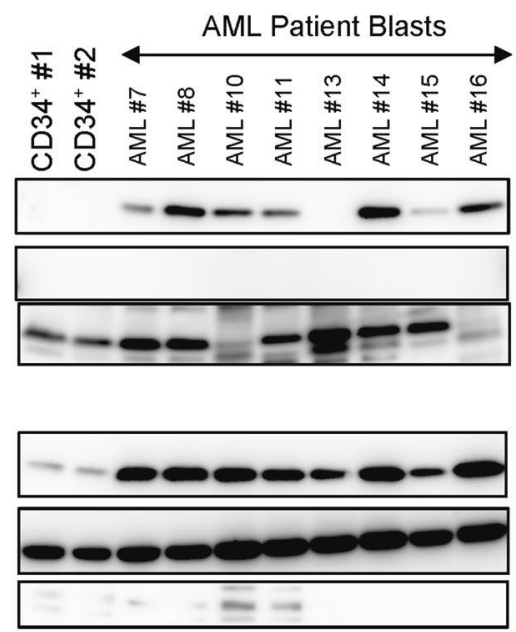

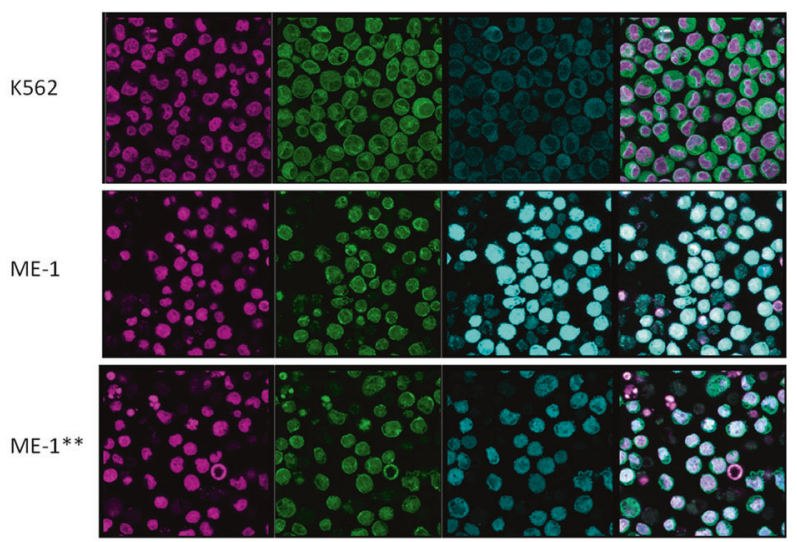

Fig. $4 \mathrm{~S} 100 \mathrm{~A} 4$ is over-expressed in the nucleus of AML blasts. a Example immunoblots showing validation of S100A4 protein expression and subcellular localization in same FAB M1 patient samples analyzed by MS. Supplementary Fig. S3 shows relative S100A4 expression in cytosol and nuclear fractions. S100A4 was upregulated in the nuclei and cytoplasm of 13/15 AML patients determined by western blot. AML samples 9,11 , and 12 were derived from patient bone marrow; all others AML samples were derived from peripheral blood. b Expression and subcellular localization of S100A4 in a cohort of leukemia cell lines. Cytosolic (C) and nuclear (N) fractions were analyzed by GAPDH and Histone $\mathrm{H} 1$ to indicate the

To correlate a transcriptome signature with TF expression we analyzed the transcriptome of AML cells and used the network-building algorithm on transcription regulation from MetaCore ${ }^{\mathrm{TM}}$ to examine whether the modulated genes are connected to TF. Several TF networks were identified but none of them correlated with dysregulated TF protein purity/relative loading of each fraction. $\mathbf{c}$ Validation and expression of endogenous S100A4 expression in K562 and ME-1 leukemic cells lines using confocal laser scanning microscopy. These cell lines have either low cytoplasmic or high nuclear protein expression of S100A4 respectively. Cells were stained with DAPI and Tubulin to define cytoplasm and nuclear compartments. Fluorescence gains were equivalent (and based on isotype controls for each panel); except for $\mathrm{ME}-1^{* *}$ whose gain was reduced to allow the visualization of S100A4 protein expression without saturation as shown in the middle panel

expression. Interestingly, 13 proteins involved in mRNA processing were shown to be dysregulated suggesting that posttranscriptional regulation of mRNAs and/or LncRNAs could play a critical role in modulating transcription. In support of this, analysis of our microarray data revealed significant differences between the transcriptome 

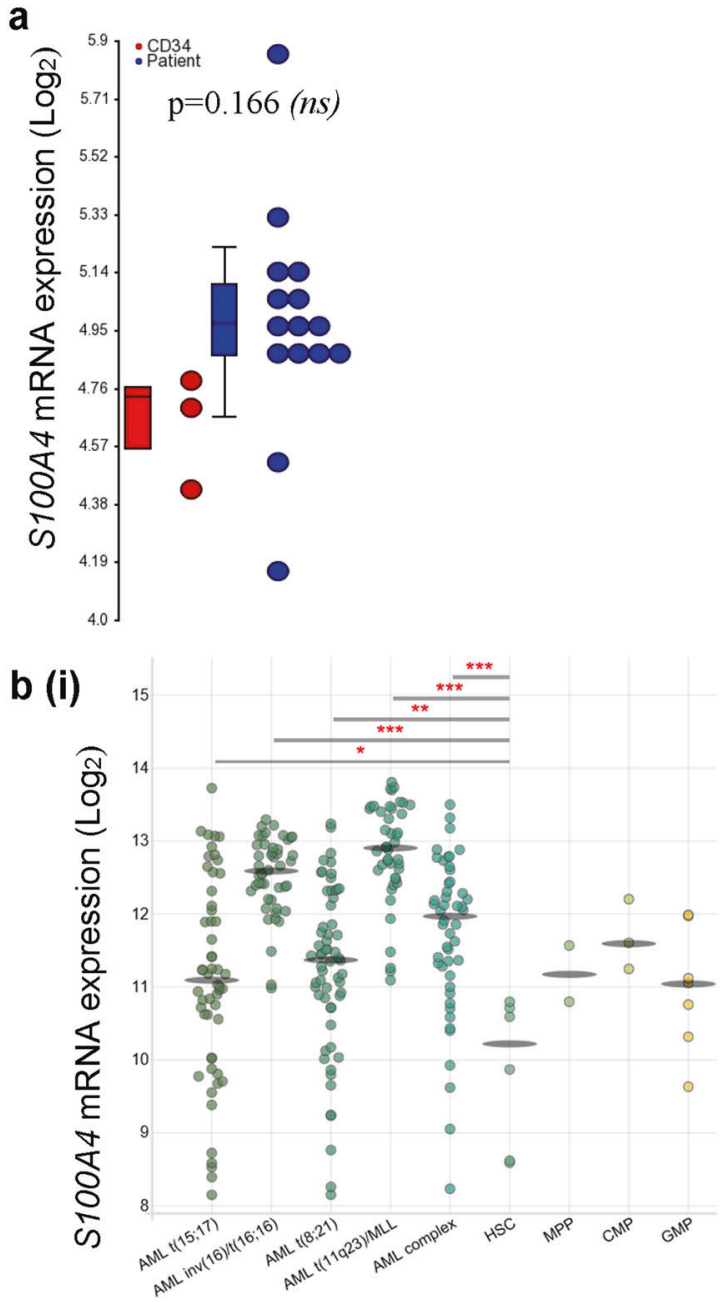

Fig. 5 Over-expression of S100A4 mRNA in AML. a Microarray data demonstrating the normalized intensity of S100A4 mRNA $\left(\log _{2}\right)$ expression in normal human $\mathrm{CD} 34^{+}$cells (red; $n=3$ ) and FAB-M1 AML $(n=15)$. RNA was isolated from samples that underwent mass spectrometry. The transcriptome of these samples were analyzed by Affymetrix Gene expression Profiling and data analyzed using Partek Genomics Suite v6. The Pearson correlation of S100A4 mRNA with protein expression was $r=0.45$ (CI $-0.206,0.827)$. b S100A4 mRNA expression data from Bloodspot [69]. (b(i)) mRNA expression level of S100A4 in different AML subtypes vs. normal human hematopoietic developmental subsets. Human normal hematopoiesis data derived

of AML cells and $\mathrm{CD} 34^{+}$cells particularly with the generation of mRNA transcripts through alternative splicing (data not shown).

We next examined which proteins were the most significantly changed in AML based on frequently of detection coupled with highest fold changes in our cohort of patients. We further focused on novel abnormalities by excluding proteins with known published associations with AML (Table 2). S100A4 was identified for further study, as the most significant, fold changing protein in AML blasts that is over-expressed in the nucleus of AML and has not been b (ii)

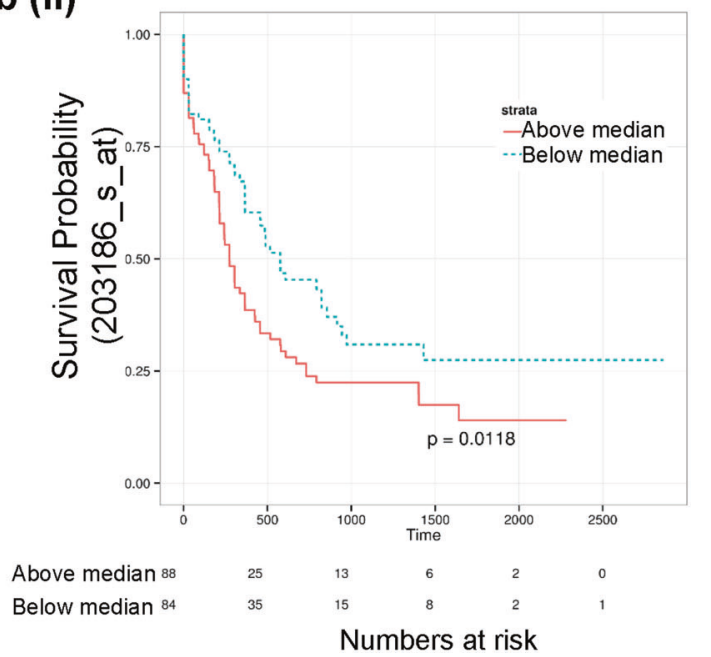

from GSE42519 [30] and human AML data derived from GSE13159 [70]. HSC, Hematopoietic stem cell $\mathrm{Lin}^{-} \mathrm{CD} 34^{+} \mathrm{CD} 38^{-} \mathrm{CD} 90^{+}$ CD45RA ${ }^{-}$; MPP, Multipotential progenitors $\mathrm{Lin}^{-} \mathrm{CD} 34^{+} \mathrm{CD} 38^{-}$ $\mathrm{CD}^{-} 0^{-}$45RA ${ }^{-}$; CMP, Common myeloid progenitor cell $\mathrm{Lin}^{-} \mathrm{CD} 34^{+}$ $\mathrm{CD}^{2} 8^{+} \mathrm{CD}^{2} 5 \mathrm{RA}^{-} \mathrm{CD} 123^{+}$; GMP, Granulocyte monocyte progenitors $\mathrm{Lin}^{-} \mathrm{CD} 34^{+} \mathrm{CD} 38^{+} \mathrm{CD} 4 \mathrm{RA}^{+} \mathrm{CD}^{+} 3^{+}$. (b(ii)) Overall survival of AML patients stratified according to S100A4 expression level using the AML TCGA dataset [31]. Statistical significance is denoted by $* P$ $<0.05 ; * * P<0.01$ and $* * * P<0.001$ analyzed by $t$-test. ns; not significant

previously associated with AML. S100A4 belongs to the S100 multigene family of calcium-binding proteins of the EF-hand type. These proteins are distributed into three main subgroups based on regulatory control within the extracellular or intracellular environments (or both). They have diverse roles in a variety of cellular processes including regulation of proliferation, cell cycle progression, apoptosis, differentiation, $\mathrm{Ca}^{2+}$ homeostasis, migration, adhesion and transcription [10, 29, 49]. S100A4 expression is found to be over-expressed in several solid tumors and has been associated with poor prognosis $[11,15,16,50,51]$. 


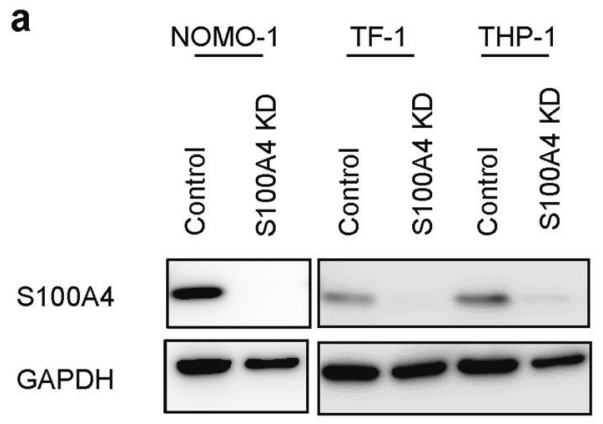

b
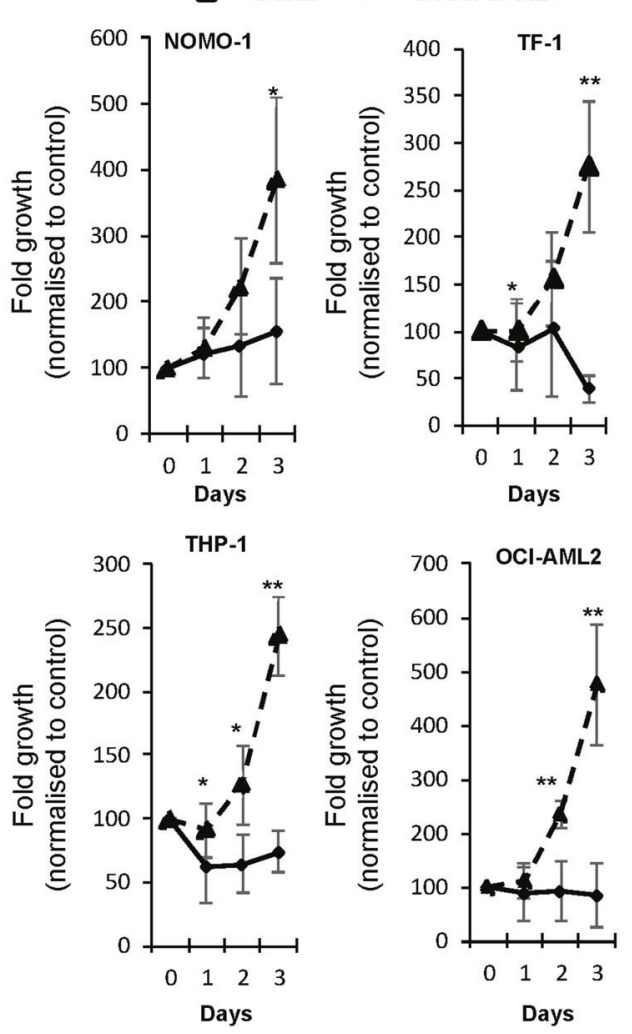

Fig. 6 S100A4 is required for cell survival in leukemia cell lines. a Example western blot showing S100A4 expression in leukemia cells with S100A4 knocked down (KD; TRCN0000416498) compared with control (targeting nonmammalian gene) using shRNA. b Summary data showing growth of leukemia lines with S100A4 KD (TRCN0000416498) compared with control over 3 days of growth following infection $(n=3$; except KG1 $(n=2)$. c, d Apoptosis was evaluated by flow cytometric analysis of APC-conjugated Annexin V binding, while simultaneously assessing membrane integrity by PI

Interestingly, preferentially expressed antigen of melanoma (PRAME) which has previously been shown to reduce tumorigenicity of leukemic cells in vivo, has also been shown to reduce expression of S100A4 [52], particularly in those leukemias associated with favorable outcome (e.g., in leukemia's harboring RUNX1-ETO and PML-RAR $\alpha$ ). More recently, $\mathrm{Xu}$ et al. demonstrated that PRAME
C

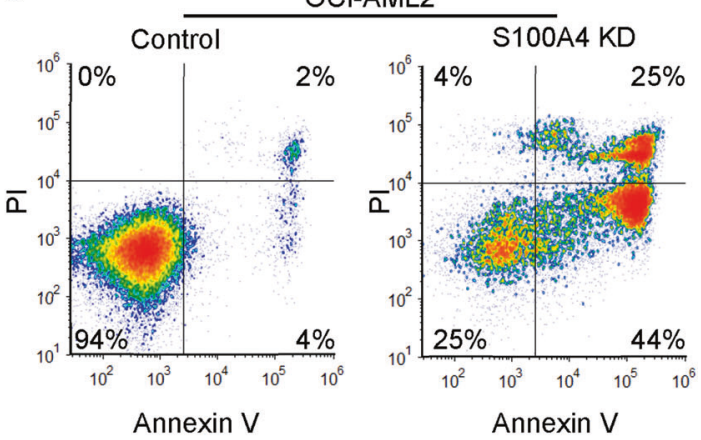

d

aControl aS100A4 KD

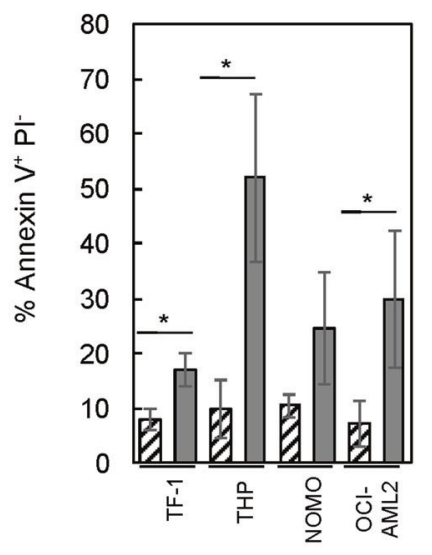

exclusion. c Example flow cytometric plots of S100A4 KD compared with control using OCI-AML2. Annexin $\mathrm{V}^{-}$and $\mathrm{PI}^{-}$negative (lowerleft quadrant), annexin $\mathrm{V}^{+}$and $\mathrm{PI}^{-}$(lower-right quadrant) and both annexin V and PI positive (upper-right quadrant) cells were considered as the viable, early-phase apoptotic, late-phase apoptotic/necrotic cells, respectively. d Summary data showing the effect of S100A4 KD on Annexin V staining in leukemia cell lines following $48 \mathrm{~h}$ post infection. Data indicates mean $\pm 1 \mathrm{SD}(n=3)$. Statistical significance is denoted by $* P<0.05 ; * * P<0.001$ analyzed by paired $t$-test

promotes apoptotic death of leukemia cells by regulating S100A4/p53 signaling [16]. Others have previously shown S100A4 to have a key role in proliferation, cell cycle progression and cell survival in transformed cells (reviewed in [53]). S100A4 has been studied in breast cancer models which have shown that over-expression of S100A4 in nonmetastatic mammary tumor cells confers a metastatic 
phenotype [54]. This is consistent with earlier studies where knock down of S100A4 has been shown to reduce the selfrenewal capability and tumorigenic properties of solid tumor cancer initiating cells $[55,56]$. It is likely that these effects are mediated through protein binding partners of S100A4; for example, in vitro studies have shown that nonmuscle myosin heavy chain IIA (NM-MHC IIA) can bind directly to S100A4 and modulate the interaction between non-muscle myosin and actin, resulting in cytoskeletal rearrangement and increased migration [57]. This would be consistent with pathway changes we observed in the nucleus of AML blasts (Fig. 2a). S100A4 has also been shown to interact directly with p53 in the nucleus and induce MDM2-dependent p53 degradation [58]. In this latter study, S100A4 knock down leads to a p53-dependent cell cycle arrest and increased cisplatin-induced apoptosis. However, in this study we did not detect p53 bound to S100A4 (data not shown). Interestingly S100A4 has previously been found to be a downstream target of CEBPA [59] and SP1 [60, 61], key hub targets identified through our transcriptome analysis.

Whilst S100A4 has been widely studied in solid tumors very little is known of its role in hematological malignancies. We show for the first time that normal CD34 ${ }^{+}$ cells and myeloid differentiated lineages express this protein in the cytosol. Knocking down expression of S100A4 in AML lines results in cell death through induction of apoptosis and hence is an attractive target for cancer therapy particularly in AML given that normal cells would be spared [62]. Increasing evidence suggests that expression and subcellular localization of several S100 proteins is different between physiological and pathological conditions. Indeed, we also observed nuclear expression changes in S100A6 and S100A11 in our data set. Interestingly, S100A8 and S100A9 have previously been shown to be abundant in myeloid cells and associated with poor prognosis in AML [63-65]; these studies focused on total expression and not subcellular expression. S100A4 is predominantly a cytosolic protein under normal physiological conditions but few studies have identified this protein in the nucleus of transformed cells [66-68]. In our cohort of AML, there were very few cell lines and patient derived blasts with no expression of S100A4 in the nucleus. It remains to be determined whether S100A4 is mislocalized to the nucleus in AML or is a result of the high expression of this protein in AML. S100A4 has been shown to undergo several posttranslational modifications in other contexts, including oxidative modification or sumoylation, which can modulate intracellular localization [67]. Nuclear localization of S100A4 in AML would facilitate regulation of gene transcription either through direct DNA binding, or through interaction with other DNA-binding proteins as previously described
[8]. However, we found little evidence of this in our transcriptome data and Metacore ${ }^{\mathrm{TM}}$ analysis; though this analysis is dependent on the level of annotation in the Clarivate knowledgebase [26]. We are currently investigating the binding partners of S100A4 that are responsible for the shuttling of this protein between the cytosplasm and nucleus or whether S100A4 binds to nuclear proteins that enhance its retention in the nucleus using proteomics.

In summary, we report the first study to use iTRAQ proteomic analysis coupled with mRNA GEP to identify several proteins that are expressed or repressed in the nucleus of AML blasts. One of these proteins, S100A4, is essential for AML cell growth and survival suggesting that therapeutically targeting S100A4 would be an effective strategy while sparing normal hemopoietic cells.

Acknowledgements The authors would like to thank Bloodwise, U.K. (13029 and 13005), Health and Care Research Wales and Prince Mohammed Medical City (PMMC), Al-Jouf, Saudi Arabia, for funding this project. NR is a Sêr Cymru II Fellow supported by Welsh Government, European Regional Development Fund. ADW was also funded by the Manchester Experimental Cancer Medicine Centre, Bloodwise, Medical Research Council, Cancer Research UK major centre award and the NIHR Manchester Biomedical Research Centre. We thank Megan Musson, Joanne Morgan and Dr Peter Giles (Cardiff University) for their technical assistance in analyzing microarray data.

\section{Compliance with ethical standards}

Conflict of interest The authors declare that they have no conflict of interest.

Publisher's note Springer Nature remains neutral with regard to jurisdictional claims in published maps and institutional affiliations.

Open Access This article is licensed under a Creative Commons Attribution 4.0 International License, which permits use, sharing, adaptation, distribution and reproduction in any medium or format, as long as you give appropriate credit to the original author(s) and the source, provide a link to the Creative Commons license, and indicate if changes were made. The images or other third party material in this article are included in the article's Creative Commons license, unless indicated otherwise in a credit line to the material. If material is not included in the article's Creative Commons license and your intended use is not permitted by statutory regulation or exceeds the permitted use, you will need to obtain permission directly from the copyright holder. To view a copy of this license, visit http://creativecommons. org/licenses/by/4.0/.

\section{References}

1. Ferrara F, Schiffer CA. Acute myeloid leukaemia in adults. Lancet. 2013;381:484-95.

2. Moarii M, Papaemmanuil E. Classification and risk assessment in AML: integrating cytogenetics and molecular profiling. Hematol Am Soc Hematol Educ Program. 2017;2017:37-44.

3. Kentsis A, Reed C, Rice KL, Sanda T, Rodig SJ, Tholouli E, et al. Autocrine activation of the MET receptor tyrosine kinase in acute myeloid leukemia. Nat Med. 2012;18:1118-22. 
4. Vogel C, Marcotte EM. Insights into the regulation of protein abundance from proteomic and transcriptomic analyses. Nat Rev Genet. 2012;13:227-32.

5. Wang X, Li S. Protein mislocalization: mechanisms, functions and clinical applications in cancer. Biochim Biophys Acta. 2014;1846:13-25.

6. Banerji V, Frumm SM, Ross KN, Li LS, Schinzel AC, Hahn CK, et al. The intersection of genetic and chemical genomic screens identifies GSK-3alpha as a target in human acute myeloid leukemia. J Clin Investig. 2012;122:935-47.

7. Reis H, Putter C, Megger DA, Bracht T, Weber F, Hoffmann $\mathrm{AC}$, et al. A structured proteomic approach identifies 14-33 Sigma as a novel and reliable protein biomarker in panel based differential diagnostics of liver tumors. Biochim Biophys Acta. 2015; 1854:641-50.

8. Bresnick AR, Weber DJ, Zimmer DB. S100 proteins in cancer. Nat Rev Cancer. 2015;15:96-109.

9. Garrett SC, Varney KM, Weber DJ, Bresnick AR. S100A4, a mediator of metastasis. J Biol Chem. 2006;281:677-80.

10. Heizmann CW, Ackermann GE, Galichet A. Pathologies involving the S100 proteins and RAGE. Subcell Biochem. 2007;45:93-138.

11. Bai H, Qian JL, Han BH. S100A4 is an independent prognostic factor for patients with lung cancer: a meta-analysis. Genet Test Mol Biomark. 2014;18:371-4.

12. Cao CM, Yang FX, Wang PL, Yang QX, Sun XR. Clinicopathologic significance of S100A4 expression in osteosarcoma. Eur Rev Med Pharm Sci. 2014;18:833-9.

13. Destek S, Gul VO. S100A4 may be a good prognostic marker and a therapeutic target for colon cancer. J Oncol. 2018;2018:1828791.

14. Zhou Y, Li Z, Ding Y, Zhang J, Yang Q, Wu Y. Overexpression of S100A4 protein may be associated with the development and progression of pancreatic cancer. J Cancer Res Ther. 2018;14 (Supplement):S159-S166.

15. Tajeddine N, Louis M, Vermylen C, Gala JL, Tombal B, Gailly P. Tumor associated antigen PRAME is a marker of favorable prognosis in childhood acute myeloid leukemia patients and modifies the expression of S100A4, Hsp 27, p21, IL-8 and IGFBP-2 in vitro and in vivo. Leuk Lymphoma. 2008;49:1123-31.

16. Xu Y, Rong LJ, Meng SL, Hou FL, Zhang JH, Pan G. PRAME promotes in vitro leukemia cells death by regulating S100A4/ p53 signaling. Eur Rev Med Pharm Sci. 2016;20:1057-63.

17. Tonks A, Pearn L, Tonks AJ, Pearce L, Hoy T, Phillips S, et al. The AML1-ETO fusion gene promotes extensive self-renewal of human primary erythroid cells. Blood. 2003;101:624-32.

18. Tonks A, Pearn L, Musson M, Gilkes A, Mills KI, Burnett AK, et al. Transcriptional dysregulation mediated by RUNX1RUNX1T1 in normal human progenitor cells and in acute myeloid leukaemia. Leukaemia. 2007;21:2495-505.

19. Morgan RG, Pearn L, Liddiard K, Pumford SL, Burnett AK, Tonks A, et al. gamma-Catenin is overexpressed in acute myeloid leukemia and promotes the stabilization and nuclear localization of beta-catenin. Leukemia. 2013;27:336-43.

20. Qadir M, Barcos M, Stewart CC, Sait SN, Ford LA, Baer MR. Routine immunophenotyping in acute leukemia: Role in lineage assignment and reassignment. Cytom B Clin Cytom. 2006;70:329-34

21. Cammenga J, Mulloy JC, Berguido FJ, MacGrogan D, Viale A, Nimer SD. Induction of C/EBPalpha activity alters gene expression and differentiation of human CD34+ cells. Blood. 2003;101:2206-14.

22. Pabst T, Mueller BU. Complexity of CEBPA dysregulation in human acute myeloid leukemia. Clin Cancer Res. 2009;15:5303-7.

23. Schwarzinger I, Valent P, Koller U, Marosi C, Schneider B, Haas $\mathrm{O}$, et al. Prognostic significance of surface marker expression on blasts of patients with de novo acute myeloblastic leukemia. J Clin Oncol. 1990;8:423-30.
24. Meldi KM, Figueroa ME. Cytosine modifications in myeloid malignancies. Pharm Ther. 2015;152:42-53.

25. Gronostajski RM. Roles of the NFI/CTF gene family in transcription and development. Gene. 2000;249:31-45.

26. Marquis M, Beaubois C, Lavallee VP, Abrahamowicz M, Danieli C, Lemieux S, et al. High expression of HMGA2 independently predicts poor clinical outcomes in acute myeloid leukemia. Blood Cancer J. 2018;8:68.

27. Xutao G, PengCheng S, Yin L, Huijuan D, Yan W, Haiqing Z, et al. BCL11A and MDR1 expressions have prognostic impact in patients with acute myeloid leukemia treated with chemotherapy. Pharmacogenomics. 2018;19:343-8.

28. Shmelkov E, Tang Z, Aifantis I, Statnikov A. Assessing quality and completeness of human transcriptional regulatory pathways on a genome-wide scale. Biol Direct. 2011;6:15.

29. Donato R, Cannon BR, Sorci G, Riuzzi F, Hsu K, Weber DJ, et al. Functions of S100 proteins. Curr Mol Med. 2013;13:24-57.

30. Rapin N, Bagger FO, Jendholm J, Mora-Jensen H, Krogh A, Kohlmann A, et al. Comparing cancer vs normal gene expression profiles identifies new disease entities and common transcriptional programs in AML patients. Blood. 2014;123:894-904.

31. Ley TJ, Miller C, Ding L, Raphael BJ, Mungall AJ, Robertson A, et al. Genomic and epigenomic landscapes of adult de novo acute myeloid leukemia. N Engl J Med. 2013;368:2059-74.

32. El Naaman C, Grum-Schwensen B, Mansouri A, Grigorian M, Santoni-Rugiu E, Hansen T, et al. Cancer predisposition in mice deficient for the metastasis-associated Mts1(S100A4) gene. Oncogene. 2004;23:3670-80.

33. Wen H, Li Y, Malek SN, Kim YC, Xu J, Chen P, et al. New fusion transcripts identified in normal karyotype acute myeloid leukemia. PLoS ONE. 2012;7:e51203.

34. Lechman ER, Gentner B, Ng SW, Schoof EM, van GP, Kennedy JA, et al. miR-126 regulates distinct self-renewal outcomes in normal and malignant hematopoietic stem cells. Cancer Cell. 2016;29:214-28.

35. Lamba JK, Pounds S, Cao X, Crews KR, Cogle CR, Bhise N, et al. Clinical significance of in vivo cytarabine-induced gene expression signature in AML. Leuk Lymphoma. 2016; 57:909-20.

36. Falini B, Martelli MP. Impact of genomics in the clinical management of patients with cytogenetically normal acute myeloid leukemia. Best Pr Res Clin Haematol. 2015;28:90-7.

37. Trost M, Sauvageau M, Herault O, Deleris P, Pomies C, Chagraoui J, et al. Posttranslational regulation of self-renewal capacity: insights from proteome and phosphoproteome analyses of stem cell leukemia. Blood. 2012;120:e17-e27.

38. Schneider RK, Schenone M, Ferreira MV, Kramann R, Joyce CE, Hartigan C, et al. Rps14 haploinsufficiency causes a block in erythroid differentiation mediated by S100A8 and S100A9. Nat Med. 2016;22:288-97.

39. Brill LM, Xiong W, Lee KB, Ficarro SB, Crain A, Xu Y, et al. Phosphoproteomic analysis of human embryonic stem cells. Cell Stem Cell. 2009;5:204-13.

40. Hu CW, Qiu Y, Ligeralde A, Raybon AY, Yoo SY, Coombes KR, et al. A quantitative analysis of heterogeneities and hallmarks in acute myelogenous leukaemia. Nat Biomed Eng. 2019. https://doi. org/10.1038/s41551-019-0387-2.

41. Kornblau SM, Tibes R, Qiu YH, Chen W, Kantarjian HM, Andreeff M, et al. Functional proteomic profiling of AML predicts response and survival. Blood. 2009;113:154-64.

42. Castella S, Bernard R, Corno M, Fradin A, Larcher JC. Ilf3 and NF90 functions in RNA biology. Wiley Interdiscip Rev RNA. 2015;6:243-56.

43. Teittinen KJ, Karkkainen P, Salonen J, Ronnholm G, Korkeamaki $\mathrm{H}$, Vihinen $\mathrm{M}$, et al. Nucleolar proteins with altered expression in leukemic cell lines. Leuk Res. 2012;36:232-6. 
44. Piccolo LL, Corona D, Onorati MC. Emerging roles for hnRNPs in post-transcriptional regulation: what can we learn from flies? Chromosoma. 2014;123:515-27.

45. Gallardo M, Lee HJ, Zhang X, Bueso-Ramos C, Pageon LR, McArthur M, et al. hnRNP $\mathrm{K}$ is a haploinsufficient tumor suppressor that regulates proliferation and differentiation programs in hematologic malignancies. Cancer Cell. 2015;28(Oct):486-99.

46. Chen KS, Lim JWC, Richards LJ, Bunt J. The convergent roles of the nuclear factor I transcription factors in development and cancer. Cancer Lett. 2017;410:124-38.

47. Grabowska MM, Elliott AD, DeGraff DJ, Anderson PD, Anumanthan G, Yamashita $\mathrm{H}$, et al. NFI transcription factors interact with FOXA1 to regulate prostate-specific gene expression. Mol Endocrinol. 2014;28:949-64.

48. Liu HY, Zhang CJ. Identification of differentially expressed genes and their upstream regulators in colorectal cancer. Cancer Gene Ther. 2017;24:244-50.

49. Marenholz I, Heizmann CW. S100A16, a ubiquitously expressed EF-hand protein which is up-regulated in tumors. Biochem Biophys Res Commun. 2004;313:237-44.

50. Ismail NI, Kaur G, Hashim H, Hassan MS. S100A4 overexpression proves to be independent marker for breast cancer progression. Cancer Cell Int. 2008;8:12.

51. Chong HI, Lee JH, Yoon MS, Suh DS, Kim K, Kim JY, et al. Prognostic value of cytoplasmic expression of S100A4 protein in endometrial carcinoma. Oncol Rep. 2014;31:2701-7.

52. Tajeddine N, Gala JL, Louis M, Van SM, Tombal B, Gailly P. Tumor-associated antigen preferentially expressed antigen of melanoma (PRAME) induces caspase-independent cell death in vitro and reduces tumorigenicity in vivo. Cancer Res. 2005;65:7348-55.

53. Fei F, Qu J, Zhang M, Li Y, Zhang S. S100A4 in cancer progression and metastasis: a systematic review. Oncotarget. 2017;8:73219-39.

54. Davies BR, Davies MP, Gibbs FE, Barraclough R, Rudland PS. Induction of the metastatic phenotype by transfection of a benign rat mammary epithelial cell line with the gene for $\mathrm{p} 9 \mathrm{Ka}$, a rat calcium-binding protein, but not with the oncogene EJ-ras-1. Oncogene. 1993;8:999-1008.

55. Saleem M, Kweon MH, Johnson JJ, Adhami VM, Elcheva I, Khan N, et al. S100A4 accelerates tumorigenesis and invasion of human prostate cancer through the transcriptional regulation of matrix metalloproteinase 9. Proc Natl Acad Sci USA. 2006;103:14825-30.

56. Lo JF, Yu CC, Chiou SH, Huang CY, Jan CI, Lin SC, et al. The epithelial-mesenchymal transition mediator S100A4 maintains cancer-initiating cells in head and neck cancers. Cancer Res. 2011;71:1912-23.

57. Palfy G, Kiss B, Nyitray L, Bodor A. Multilevel changes in protein dynamics upon complex formation of the calcium-loaded
S100A4 with a nonmuscle myosin IIA tail fragment. Chembiochem. 2016;17:1829-38.

58. Orre LM, Panizza E, Kaminskyy VO, Vernet E, Graslund T, Zhivotovsky B, et al. S100A4 interacts with p53 in the nucleus and promotes p53 degradation. Oncogene. 2013;32:5531-40.

59. Venkov CD, Link AJ, Jennings JL, Plieth D, Inoue T, Nagai K, et al. A proximal activator of transcription in epithelialmesenchymal transition. J Clin Investig. 2007;117:482-91.

60. Cohn MA, Hjelmso I, Wu LC, Guldberg P, Lukanidin EM, Tulchinsky EM. Characterization of Sp1, AP-1, CBF and KRC binding sites and minisatellite DNA as functional elements of the metastasis-associated mts1/S100A4 gene intronic enhancer. Nucleic Acids Res. 2001;29:3335-46.

61. Kroliczak W, Pietrzak M, Puzianowska-Kuznicka M. P53dependent suppression of the human calcyclin gene (S100A6): the role of Sp1 and of NFkappaB. Acta Biochim Pol. 2008;55:559-70.

62. Liu J, Fu S, Xu Y, Zheng Z. RNA interference targeting inhibition of S100A4 suppresses cell growth and promotes apoptosis in human laryngeal carcinoma Hep2 cells. Mol Med Rep. 2014;10:1389-94.

63. Nicolas E, Ramus C, Berthier S, Arlotto M, Bouamrani A, Lefebvre $\mathrm{C}$, et al. Expression of S100A8 in leukemic cells predicts poor survival in de novo AML patients. Leukemia. 2011;25:57-65.

64. Stewart HJS, Chaudry S, Crichlow A, Luiling FF, Chevassut TJT. BET inhibition suppresses S100A8 and S100A9 expression in acute myeloid leukemia cells and synergises with daunorubicin in causing cell death. Bone Marrow Res. 2018;2018:5742954.

65. Laouedj M, Tardif MR, Gil L, Raquil MA, Lachhab A, Pelletier $\mathrm{M}$, et al. S100A9 induces differentiation of acute myeloid leukemia cells through TLR4. Blood. 2017;129:1980-90.

66. Kikuchi N, Horiuchi A, Osada R, Imai T, Wang C, Chen X, et al. Nuclear expression of S100A4 is associated with aggressive behavior of epithelial ovarian carcinoma: an important autocrine/paracrine factor in tumor progression. Cancer Sci. 2006;97:1061-9.

67. Miranda KJ, Loeser RF, Yammani RR. Sumoylation and nuclear translocation of S100A4 regulate IL-1beta-mediated production of matrix metalloproteinase-13. J Biol Chem. 2010;285:31517-24.

68. Flatmark K, Pedersen KB, Nesland JM, Rasmussen H, Aamodt G, Mikalsen SO, et al. Nuclear localization of the metastasis-related protein S100A4 correlates with tumour stage in colorectal cancer. J Pathol. 2003;200:589-95.

69. Bagger FO, Sasivarevic D, Sohi SH, Laursen LG, Pundhir S, Sonderby CK, et al. BloodSpot: a database of gene expression profiles and transcriptional programs for healthy and malignant haematopoiesis. Nucleic Acids Res. 2016;44:D917-D924.

70. Kohlmann A, Kipps TJ, Rassenti LZ, Downing JR, Shurtleff SA, Mills KI, et al. An international standardization programme towards the application of gene expression profiling in routine leukaemia diagnostics: the Microarray Innovations in Leukemia study prephase. Br J Haematol. 2008;142:802-7. 